\title{
Analisis Kinerja Co-Creation terhadap Customer Value Serta Dampaknya Pada Kepuasan Pelanggan" (Survei Pada Pengguna Sim card XL di Fanpage XL Interactive)
}

\author{
Rubby Rahman Tsani $^{1}$, Ratih Hurriyati ${ }^{2}$ \\ Mahasiswa Magister Manajemen Bisnis \\ Sekolah Pasca Sarjana Universitas Pendidikan Indonesia
}

\begin{abstract}
Abstrak
tujuan dari penelitian ini adalah untuk mengetahui; 1) Memperoleh gambaran Kinerja pelaksanaan Co Creation pada produk XL, Kesesuaian Customer Value, dan Tingkat Kepuasan Pelanggan Pengguna Sim Card XL. 2) Memperoleh gambaran Pengaruh dari Kinerja Co Creation pada produk XL Terhadap Kesesuaian Customer Value Pengguna Sim Card XL, 3) Memperoleh gambaran Pengaruh dari Kinerja Co-Creation terhadap tingkat Kepuasan Pelanggan Pengguna Sim Card XL; serta 4) Memperoleh gambaran Pengaruh dari Kesesuaian Customer Value terhadap tingkat Kepuasan Pelanggan Pengguna Sim Card XL

Objek dari penelitian ini adalah tanggapan pengguna mengenai co creation terhadap customer value dan dampaknya pada kepuasan pelanggan pengguna sim card XL. Adapun metode penelitiannya menggunakan deskriptif verifikatif. Sumber data yang dipergunakan adalah primer dan sekunder. Dari populasi 5.716 anggota serta sampel penelitian sejumlah 100 anggota. Teknik pengambilan data dilakukan melalui wawancara, observasi kuesioner dan studi literatur. Untuk mengukur besarnya pengaruh Kinerja Co Creation terhadap Customer Value Serta Dampaknya Pada Kepuasan Pelanggan, digunakan teknik analisis jalur path (analisis jalur) dengan menggunakan Software SPSS versi 16.0

Hasil penelitian mengungkapkan bahwa pelaksanaan Co Creation dinilai pengguna cukup tinggi, Customer Value di nilai tinggi sedangkan Kepuasan Pelanggan dinilai oleh pengguna dengan nilai tingkat kepuasan tinggi.
\end{abstract}

Kata kunci : Co Creation, Customer Value dan Kepuasan Pelanggan

\section{PENDAHULUAN}

Kondisi pangsa pasar yang kompetitif terlihat pada tinggi rendahnya market share industri telekomunikasi di Indonesia yang cenderung fluktuatif. Market share dapat menunjukan tingkat keputusan menggunakan pada pelanggan. Berikut ini market share industri telekomunikasi dapat dilihat pada Tabel 1.1

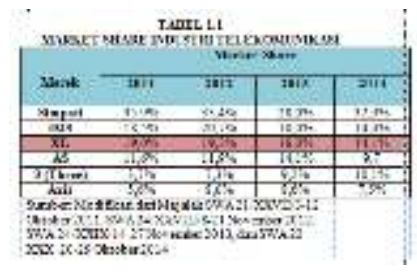

telekomunikasi seluler, dimana XL dalam pangsa pasar mengalami penurunan secara fluktuatif. Penurunan ini menjadi sebuah acaman bagi XL karena hal ini akan berdampak pada jumlah pelanggan yang dimiliki.
Survei yang dilakukan oleh Majalah Swa untuk mengukur tingkat kepuasan terhadap produk dengan kriteria memberikan kualitas layanan QSS (Quality Satifaction Score), nilai kepuasan pelanggan terhadap harga yang mereka bayar VSS (Value Satisfaction Score), dan keyakinan pelanggan bahwa merek yang digunakan sebagai merek terbaik PBS (Perceived Best Score). Berikut Tabel 1.3 Tabel Kinerja Kepuasan Pelanggan Terhadap Produk.

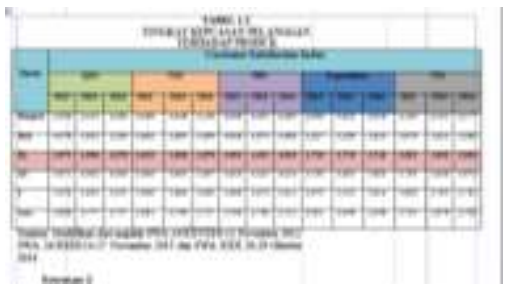

menilai kinerja kepuasan pelanggan, tingkat kualitas produk yang dirasakan pelanggan, tingkat kepuasan harga yang dibayarkan, hingga keyakinan penggunaan merek terbaik dari berbagai kompetitor dengan beberapa indikator yang telah di uraikan 
sebelumnya mendapatkan tanggapan dengan nilai yang variatif, termasuk XL. Pada Industri telekomunikasi ini, aktifitas kolaborasi kreatif antara konsumen dan produsen dalam menciptakan produk merupakan sebuah hal yang baru di implementasikan, maka dari itu peneliti tertarik memilih XL untuk diteliti. Berdasarkan latar belakang di atas, penulis bermaksud melakukan penelitian dengan judul "Analisis CoCreation terhadap Customer Value Serta Dampaknya Pada Kepuasan Pelanggan (Survei Pada Pengguna Sim card XL di Fanpage XL Interactive)". Penurunan kepuasan di beberapa indikator ini merupakan ancaman bagi perusahaan karena pelanggan dapat merasa tidak puas dan akan berpindah ke provider lain

\section{KERANGKA PENELITIAN \& HIPOTESIS}

Coates (2009:3) menjelaskan "Co-creation is an active, creative and social process, based on collaboration between producers and users, that is initiated by the firm to generate value for customers". Strategi co-creation tersebut merupakan suatu strategi untuk membangun karakter dan memperbaiki kinerja produk dengan kreatif melalui kolaborasi baik dengan para ahli atau pelanggan, sehingga dapat mendorong penjualan dan mampu meningkatkan pasar potensial Prahalad dan Ramaswamy dalam Kertajaya (2009: 132) berpendapat "apabila perusahaan sudah menjalankan proses co-creation dengan baik dari produk nya akan lebih baik dari produk yang dihasilkan melalui new product development". Kotler dan Keller (2007:238) mengemukakan bahwa kepuasan pembeli adalah fungsi dari seberapa sesuainya harapan pembeli produk dengan kinerja yang dipikirkan pembeli atas produk tersebut. Menurut Leo YM Sin et all (2004:47) Kepuasan pelanggan dapat diciptakan melalui customer value dari para pelanggannya. Semakin baik nilai pelanggan, akan semakin tinggi pula kepuasan pelanggan. Slater dan Narver (2004:47) mengatakan konsep nilai pelanggan mengindikasikan suatu hubungan yang kuat terhadap kepuasan pelanggan, dimana konsep tersebut menggambarkan pertimbangan yang evaluatif pada pelanggan terhadap produk yang ditawarkan.

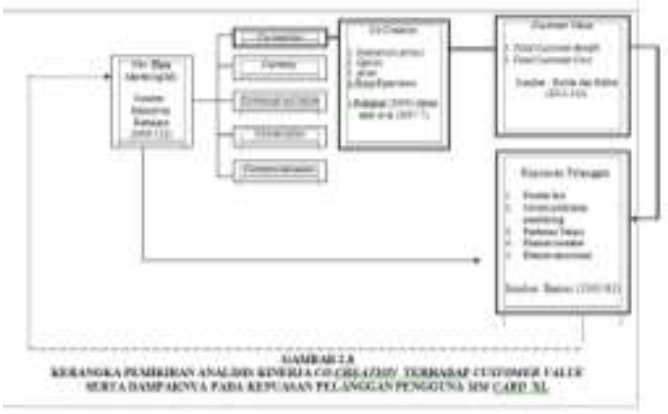

1. Terdapat pengaruh dari Kinerja pelaksanaan Co Creation Terhadap Kesesuaian Customer Value

2. Terdapat Pengaruh dari Kinerja pelaksanaan Co Creation Terhadap Tingkat Kepuasan pelanggan

3. Terdapat Pengaruh dari Kesesuaian Customer Value terhadap tingkat Kepuasan Pelanggan Pengguna Sim Card XL.

\section{METODE PENELITIAN}

Penelitian ini menganalisis Co Creation terhadap Customer value dan dampaknya pada kepuasan pelanggan. Adapun yang menjadi objek penelitian sebagai variabel bebas (independent variable) yaitu Co-creation memiliki dimensi dasar yaitu Interaction Across, Option, Acces dan Price experience, dan yang menjadi variabel perantara (intervening variable) adalah customer value yang terdiri dari total benefit dan total customer cost. Teknik analisis data yang digunakan untuk melihat analisis Co-Creation (X) terhadap customer value $(\mathrm{Y})$ yang terdiri dari total customer benefit (Y1), total customer cost (Y2), serta dampaknya pada kepuasan pelanggan (Z), adalah analisis verifikatif, maka dilakukan analisis jalur (path analysis).

\section{HASIL DAN PEMBAHASAN}

Pengujian mengenai pengaruh Co-creation terhadap Customer Value dan dampaknya pada Kepuasan Pelanggan dilakukan untuk mengetahui besarnya pengaruh langsung dan tidak langsung variabel Co-Creation (X) terhadap Customer Value (Y) serta dampaknya pada Kepuasan Pelanggan (Z). 


\begin{tabular}{|c|c|c|c|c|c|c|}
\hline \multicolumn{7}{|c|}{ ANOVA ${ }^{b}$} \\
\hline Model & & $\begin{array}{r}\text { Sum of } \\
\text { Squares }\end{array}$ & df & Mean Square & $\mathrm{F}$ & Sig. \\
\hline 1 & $\begin{array}{l}\text { Regression } \\
\text { Residual } \\
\text { Total }\end{array}$ & $\begin{array}{r}1632,929 \\
697,387 \\
2330,316\end{array}$ & $\begin{array}{r}2 \\
97 \\
99\end{array}$ & $\begin{array}{r}816,465 \\
7,190\end{array}$ & 113,563 &, $000^{a}$ \\
\hline
\end{tabular}

b. Dependent Variable: $Z$

$$
\begin{aligned}
& F=\frac{(n-k-1) \sum_{i=1}^{n} P_{Y X i} r_{Y X 1}}{k\left\{1-\sum_{i=1}^{n} P_{Y X i} r_{Y X 1}\right\}} \\
& F=\frac{(100-2-1) \times 0,837}{1\{1-0,837\}}=113,563
\end{aligned}
$$

Uji statistik di atas mengikuti distribusi F-Snodecor dengan $\alpha=5 \%$, derajat kebebasan $\mathrm{db}_{1}=2$, dan $\mathrm{db}_{2}=$ 100-2-1 = 97, diperoleh $\mathrm{F}$ tabel = 3,090.

Dari hasil di atas dapat dilihat bahwa $\mathrm{F}$ hitung $>\mathrm{F}$ tabel $(113,563>3,090)$ signifikan sehingga sesuai dengan kriteria uji simultan adalah $\mathrm{H}_{0}$ ditolak, artinya terdapat pengaruh variabel co creation $(\mathrm{X})$ terhadap kepuasan pelanggan (Z) dengan melalui customer value $(\mathrm{Y})$.

\section{KESIMPULAN}

Kinerja co creation pada produk XL yang terdiri dari Interaction Across, Option, Acces dan Price experience. Penilaian pada dimensi accses memiliki dimensi terbesar dalam menciptakan customer value dan berdampak pada kepuasan pelanggan. Sedangkan nilai terkecil ada pada dimensi option.

Customer value yang memperoleh nilai tertinggi yaitu dimensi total customer cost, sebaliknya dimensi total customer benefit mendapatkan skor terendah.

Kepuasan pelanggan yang terdiri dari dimensi Produk Inti, Sistem pelayanan pendukung, Performa Teknis, Elemen interaksi, Elemen emosional. nilai ratarata paling tinggi adalah dimensi Produk atau Jasa Inti sedangkan dimensi kepuasan pelanggan yang terendah adalah dimensi Elemen-Elemen Interaksi dengan Pelanggan.

\section{REKOMENDASI}

Strategi yang baik dilakukan pada masa yang akan datang dengan kondisi perkembangan teknologi yang
Tabel di atas dapat diketahui bahwa total koefisien jalur dari co-creation terhadap customer value adalah sebesar 0.677 sehingga dapat diketahui nilai pengaruh melalui rumus:

$$
\begin{aligned}
R^{2} & =r_{y x}{ }^{2} \times 100 \% \\
& =(0,837)^{2} \times 100 \% \\
& =70,10 \%
\end{aligned}
$$

Berdasarkan analisis di pada dua sub struktur di atas, maka secara keseluruhan dapat digambarkan model hubungan yang terjadi sebagai berikut Selanjutnya perhitungan statistik yang didasarkan pada angka dari masing-masing variabel, yang telah di transformasi berdasarkan perhitungan yang dilakukan dengan program yang ada dalam SPSS 16.0

\begin{tabular}{|l|r|r|r|r|}
\multicolumn{7}{c}{ Model Summary } \\
\hline Model & $\mathrm{R}$ & R Square & $\begin{array}{c}\text { Adjusted } \\
\text { R Square }\end{array}$ & $\begin{array}{r}\text { Std. Error of } \\
\text { the Estimate }\end{array}$ \\
\hline 1 &, $837^{\mathrm{a}}$ &, 701 &, 695 & 2,68134 \\
\hline
\end{tabular}

a. Predictors: (Constant), $Y, X$

semakin cepat berubah dan semakin mutakhir, maka perusahaan telekomunikasi seluler agar mampu lebih kreatif dalam memilih alat-alat pemasaran. Saat ini selain mengandalkan penekanan harga dalam menghadapi persaingan tidak lagi menjadi jaminan pelanggan akan menggunakan layanan dan akan merasa puas juga. Perusahaan harus mampu mengalihkan persaingan kea rah yang berbeda dengan begitu akan semakin mendorong tumbuhnya ide-ide kreatif dari internal perusahaan dalam merestrukturisasi nilai sebuah produk dan layanan, perusahaan juga akan mampu menciptakan sebuah tren yang baru, mengubah cara pandang sebuah industri yang sudah baku. Restrukturisasi nilai pada produk yang tetap berdasarkan pada kebutuhan dan keinginan pelanggan dengan diterjemaahkan secara kreatif, inovatif dan efektif oleh setiap perusahaan telekomunikasi seluler akan menghadirkan sebuah diferensiasi nilai yang baru dari operator seluler untuk pelanggan dalam rangka memberikan sebuah 
pelayanan dan kepuasan bagi pelanggan.

\section{DAFTAR PUSTAKA}

Audhesh K. Paswan, Nancy Spears, Gopala Ganesh. 2007, The effects of obtaining one's preferred service brand on consumer satisfaction and brand loyalty, The Journal of Services Marketing, Santa Barbara: 2007. Vol. 21, Iss. 2; pg. 75.

Informatics

Kaminski, J.(2009). wave of co-creation. Online Journal of Nursing

Kotler, Philip \& Kevin L. Keller. (2007). Marketing Management, $12^{\text {th }} \quad$ Edition Pearson Internasional Edition, New Jersey: Prentice Hall.

Kotler, Philip and Amstrong Gary. (2011). Marketing An Introduction Tenth Edition. New Jersey:Pearson Education, Inc.

Kotler, Philip dan Kevin Lane Keller (2009). Manajemen Pemasaran Edisi 13 Jilid 1. Jakarta: PT. Erlangga

Kotler, Philip, Gary Amstrong. (2008). Principles of Marketing, New Jersey:Pearson Prentice Hall

Maas, Peter dan Graft, Albert. (2007). "Customer Value Analysis in Financial Services.36, 1-21

Payne, A., and Frow, P,(2005). A strategic framework for customer relationship

Shanker, Aparna. (2012). Strategic Marketing. A Literatural Review on Definitions, Concepts and Boundaries". 41940, 1-40

Thorsten Hennig Thurau and Alexander Klee, 1997, The Impact of Customer Satisfaction and Relationship Quality on Customer Retention: A Critical

\section{Majalah}

Majalah Marketing Februari 2014,

Marketing 02/XV/Februari 2015

Swa XXXI/8-12 Januari 2015

SWA XXX 20-29 Oktober 2014

Swa XXX/9-22 Januari 2014

SWA 21/XXVII/3-12 Oktober 2011,

SWA 24/XXVIII/8-21 November 2012

dan SWA 24/XXIX/14-27 November 2013

Marketing 02/XII/ Februari 2012

SWA 21/XXVII/3-12 Oktober 2011

SWA 24/XXVIII/8-12 November 2012

SWA 24/XXIX/14-27 November 2013 